\title{
Foucault e a História da Educação brasileira: dos usos possíveis do procedimento genealógico
}

\author{
Foucault y la historia de la Educación Brasileña: \\ de los usos posibles del procedimiento genealógico \\ Foucault and the brazilian History of Education: \\ the possible uses of genealogical procedure \\ Julio Groppa Aquino \\ Universidade de São Paulo (Brasil) \\ Bolsista de Produtividade em Pesquisa do CNPq \\ https://orcid.org/0000-0002-7912-9303 \\ http://lattes.cnpq.br/1124623998211027 \\ groppaq@usp.br \\ Flávio Tito Cundari da Rocha Santos \\ Universidade de São Paulo (Brasil) \\ https://orcid.org/0000-0003-4273-833X \\ http://lattes.cnpq.br/1146947200426347 \\ flavio.tito@usp.br
}

\section{Resumo}

Sabe-se que Nietzsche, a genealogia, a história, texto publicado em 1971, consiste na materialização de um deslocamento indelével do procedimento investigativo foucaultiano, o qual suscitou, em contrapartida, uma série de controvérsias com os historiadores de então, sem ter arrefecido nas últimas décadas. Na esteira de tal horizonte, o presente estudo propõe-se a perspectivar as repercussões do legado foucaultiano e, em particular, os usos da noção de genealogia na produção bibliográfica em História da Educação veiculada, entre 1997 e 2017, nos três periódicos brasileiros voltados especificamente ao campo histórico-educacional. Para tanto, operou-se uma análise atenta ao conjunto e às especificidades de 42 artigos selecionados, de modo a dar a ver movimentos simultâneos, não obstante descentrados. As conclusões voltam-se às circunstâncias e condições que permitiriam determinado tipo de exercício investigativo de matriz historial ser designado foucaultiano.

Palavras-chave: História da Educação. Genealogia. Michel Foucault. 


\begin{abstract}
It is known that Nietzsche, genealogy, history, text published in 1971, consists in the materialization of an indelible displacement of the Foucauldian investigative procedure, which, on the other hand, provoked a series of controversies with the historians of that time, without having decreased in recent decades. In the wake of this horizon, the present study aims to analyze the repercussions of the Foucauldian legacy and, in particular, the uses of the notion of genealogy in the bibliographic production in History of Education, between 1997 and 2017, in the three Brazilian journals specifically addressed to the historical-educational field. In order to do so, an attentive analysis to the set and specificities of 42 selected articles was performed, in order to reflect simultaneous, but decentralized movements. The conclusions point to the circumstances and conditions that would allow a certain type of investigative exercise of historical background to be designated Foucauldian.
\end{abstract}

Keywords: History of Education. Genealogy. Michel Foucault.

\title{
Resumen
}

Se sabe que Nietzsche, la genealogía, la historia, texto publicado en 1971, consiste en la materialización de un desplazamiento indeleble del procedimiento investigativo foucaultiano, el cual suscitó, en contrapartida, una serie de controversias con los historiadores de entonces, sin haber disminuido en las últimas décadas. En el marco de este horizonte, el presente estudio se propone analizar las repercusiones del legado foucaultiano y, en particular, los usos de la noción de genealogía en la producción bibliográfica en Historia de la Educación, entre 1997 y 2017, en los tres periódicos brasileños orientados específicamente al campo históricoeducativo. Para ello, se operó un análisis atenta al conjunto ya las especificidades de 42 artículos seleccionados, con vistas a dar a ver movimientos simultáneos, no obstante descentrados. Las conclusiones se vuelven a las circunstancias y condiciones que permitirían determinado tipo de ejercicio investigativo de matriz historial ser designado foucaultiano.

Palabras clave: Historia de la educación. Genealogía. Michel Foucault. 
$\mathrm{Eu}$ me interesso muito pelo trabalho que os historiadores fazem, mas quero fazer outro.

Michel Foucault

O presente artigo empenha-se em descrever e analisar as repercussões do legado de Michel Foucault e, em particular, os possíveis usos do procedimento genealógico na produção bibliográfica em História da Educação nas duas últimas décadas (1997-2017) veiculada respectivamente nos três periódicos brasileiros mais influentes da área, desde sua fundação: História da Educação (1997), Revista Brasileira de História da Educação (2001) e Cadernos de História da Educação (2002).

Dessa maneira, tenciona-se dar continuidade e, ao mesmo tempo, ampliação a semelhante iniciativa a cargo de José G. Gondra (2005), a qual teve como objeto de análise a produção até 2004 em dois dos três periódicos ora focalizados.

O percurso argumentativo aqui eleito inclui, primeiramente, a retomada da noção de genealogia no pensamento do intelectual francês, em sua vinculação ao aporte teórico nietzschiano. Em seguida, os debates entre Foucault e os historiadores são revisitados sumariamente, para, adiante, o campo empírico eleito ser escrutinado.

\section{Foucault e a genealogia}

O início da década de 1970 testemunhou o ponto mais alto, talvez, da relação entre Foucault e o pensamento nietzschiano, com a aparição de Nietzsche, a genealogia, a história (FOUCAULT, 2008a), escrito basilar para a compreensão do chamado giro genealógico nas investigações do autor francês. Somam-se a isso um curso sobre Nietzsche e a genealogia proferido em Vincennes em 1969, assim como seu curso inaugural no Collège de France (FOUCAULT, 2018), ocorrido entre dezembro de 1970 e março do ano seguinte, em que figuraram contrapostos os paradigmas filosóficos defendidos por Aristóteles e aqueles formulados por Nietzsche. Tratava-se, para Foucault (apud DEFERT, 2014, p. 26), do fascínio por "uma morfologia da vontade de saber na civilização europeia que se deixou de lado em favor de uma análise da vontade de poder", tal como revelou em uma carta datada de 1967, pouco antes de encerrar a redação de A arqueologia do saber (FOUCAULT, 2014).

A maneira como aí se viu justificado o interesse de Foucault pelo filósofo alemão dava conta de uma longa relação com este, iniciada já na década de 1950 por influência do contato com a obra de Georges Bataille, e consecutivamente ressignificada ao longo das pesquisas de Foucault. Em 1953 Foucault ministrara um curso em Lille, abordando o filósofo em algumas das aulas. Em 1966, tornou-se responsável, junto com Deleuze, pela edição em francês das obras completas de Nietzsche. Sua relação com o filósofo, entretanto, não se esgotaria no âmbito intelectual. Ainda em 1966, Foucault instalou-se em uma vila costeira da Tunísia, conforme descreve Daniel Defert (2014, p. 23), “[...] esforçando-se, segundo o voto de Nietzsche, para tornar-se cada dia um pouco mais grego, esportivo, bronzeado, ascético, ele inaugura uma nova estilização de sua existência".

Se, à época, o mote de seu endereçamento a Nietzsche era a inquietação em torno de como a escrita se vinculava à loucura (FOUCAULT, 2014b) bem como o ensejo de elaborar uma história da razão (FOUCAULT, 2008b), tal interesse deslocar-se-ia, mais tarde, para a investigação da problemática da verdade, isto é, o dizer tido por verdadeiro em sua conexão com as formas de reflexividade de si sobre si. 
A relativa assiduidade das remissões a Nietzsche, concentradas na década de 1960 e na primeira metade da década de 1970 - em que os debates acerca da vontade de saber seriam retomados, em 1973, no curso A verdade e as formas jurídicas (2001) proferido no Brasil -, arrefeceu nos anos que se seguiram; fato reconhecido pelo próprio Foucault (2008b), em 1983, ao declarar que não lia Nietzsche havia vários anos. Paradoxalmente, o emudecimento do alemão nos textos de Foucault ocorreu no momento em que vieram a lume cursos e livros associados diretamente à empreitada genealógica do francês, cujo cerne consistiria na dita última fase do pensador, a partir do curso Do governo dos vivos (FOUCAULT, 2014a).

$\mathrm{O}$ aparente descompasso entre a rarefação das referências a Nietzsche e a incorporação do referencial genealógico aos procedimentos adotados por Foucault foram matéria das reflexões empreendidas por Vânia Dutra de Azeredo (2014). Visando dirimir tal paradoxo, a autora considerou ser possível dividir o pensamento do professor do Collège de France em dois momentos no que tange às interações com o referencial nietzschiano.

A eles [escritos sobre Nietzsche] se seguiu o silêncio do comentador para a gestação do filósofo através de uma mudança de método que abandona o trabalho de interpretação de textos. Por isso, o tratamento de Nietzsche como instrumento de pensamento. A partir de um dado momento, Foucault vale-se de Nietzsche para pensar as próprias questões filosóficas dele e, com isso, passa a realizar uma genealogia da moral. (AZEREDO, 2014, p. 58).

Tomando como objeto de análise Nietzsche, Freud, Marx (FOUCAULT, 2008d), de 1967, e Nietzsche, a genealogia, a história (FOUCAULT, 2008a), de 1971, a autora localizou no intervalo que separa os dois textos a inflexão entre o Foucault da interpretação e o da genealogia, atribuindo ao segundo um fazer guiado por Nietzsche.

$\mathrm{O}$ argumento que faz derivar a genealogia foucaultiana daquela empreendida por Nietzsche e que tem o texto de 1971 como baliza, encontra-se largamente difundido entre aqueles que se interessaram pela trajetória foucaultiana. Entre eles, Alexandre Filordi de Carvalho (2012) ressalta as semelhanças entre a operação genealógica de Foucault e aquela de Nietzsche, tomando aquele como continuador dos passos deste.

Assumindo-se francamente um leitor de Nietzsche e, mais do que isto, valendo-se dele como um interlocutor estimado e um potencializador crítico das condições pelas quais o homem da atualidade foi se (re)inventando - o célebre rosto do homem grafado na orla do mar, prestes a desvanecer-se -, Foucault vai mesmo definir as condições metodológicas de seu empreendimento filosófico: fazer filosofia fazendo história, e desta a própria filosofia (CARVALHO, 2012, p. 225).

Já Scarlett Marton (1985), reconhecendo haver no pensamento de Foucault certa iluminação das ideias de Nietzsche, ocupa-se, contudo, dos aspectos da obra do francês que lhe parecem funcionar em oposição à filosofia do alemão, especialmente no que se refere à descaracterização do caráter cosmológico da teoria nietzschiana das forças - esta fundada, segundo a autora, na tematização da vida como pluralidade de forças. Tal incongruência, no entanto, é explicada pela aposta de Foucault em conferir centralidade à relação entre genealogia e história, não contemplando assim considerações sobre o mundo inorgânico. Com isso, o duplo flanco da genealogia foucaultiana - um filosófico e outro historiográfico - sustentaria a particularidade de seu empreendimento (MARTON, 1985). 
Seguindo a hipótese formulada por Marton, enfocaremos, a seguir, a relação entre história e genealogia em Foucault, de modo a situar as principais reverberações de seu pensamento nos meios historiográficos. Para isso, guiamo-nos pelas considerações de Paul Veyne em Foucault revoluciona a história, as quais demarcam o contexto de recepção da genealogia foucaultiana entre os historiadores.

Foucault ainda é historiador? Não há resposta, verdadeira nem falsa, para essa pergunta, pois a própria história é um desses falsos objetos naturais: ela é o que se faz dela, não deixou de se modificar, ela não prospecta um horizonte eterno: o que Foucault faz se chamará história e, ao mesmo tempo, será história, se os historiadores se apossarem do presente que ele lhes faz e não o considerarem como uvas verdes. (VEYNE, 1982, p. 181).

\section{Foucault, a história e os historiadores}

A constatação de Veyne acerca da visão dos historiadores sobre Foucault valida a percepção quanto à dupla vinculação entre história e filosofia, permitindo antever o caráter tenso da relação de Foucault com boa parte dos historiadores de sua época. Isso porque a noção de genealogia evocada pelo pensador contrapõe-se à linearidade das narrativas historiográficas, as quais, segundo ele, seriam responsáveis por uma vinculação essencialista entre o presente e o passado. Fundando-se na investigação das condições de proveniência e emergência de dado acontecimento - em detrimento de uma busca por sua origem; esta figurando como uma noção associada a uma concepção teleológica da história, da qual Foucault se afasta -, o genealogista depararia não com um segredo essencial das coisas, mas com o fato de que estas "[...] são sem essência ou que sua essência foi construída peça por peça a partir de figuras que lhe eram estranhas" (FOUCAULT, 2008a, p. 262).

Tal premissa adquire maior clareza quando situada a partir da noção de diferença última empregada por Veyne (2009) para descrever o ponto de vista foucaultiano, a qual descreve um esforço de apercepção capaz de despojar os objetos históricos de sua roupagem historiográfica. Dito de outro modo, trata-se do esforço de perspectivar também o próprio saber em torno desses objetos, tornados objetivações. Tome-se como exemplo a sexualidade. Seria necessário, de acordo com tal modo de pensamento, abdicar de tomar dita temática como algo idêntico em si mesmo que teria atravessado o tempo de modo invariante ou, ainda, relativo. Ao contrário, tratase de circunscrever as experiências descontínuas em que as práticas sexuais se inscreveram: respectivamente, a aphrodísia greco-romana, a carne medieval e a sexualidade moderna - três domínios práticos não coincidentes entre si, claro está.

Tal como Philippe Artières (2016, p. 387) bem o caracteriza, “[...] Foucault convida aos atalhos. Ele ama ultrapassar as grandes repartições operadas pela disciplina histórica. Nada de Renascimento ou Revolução. Ele nos obriga a nos desprendermos de nossas categorias históricas".

Na contramão do uso de determinados crivos analíticos alçados ao status de categorias universais - como a sociedade, a religião ou mesmo o sujeito -, empregadas usualmente não apenas pelos historiadores, mas também pelos operadores de outros campos do saber humanístico, Foucault (2008c, p. 5) opta partir

[...] da decisão, ao mesmo tempo teórica e metodológica, que consiste em dizer: suponhamos que os universais não existem; e formulo nesse momento a questão à história e aos historiadores: como vocês podem escrever a história, se não admitem a priori que algo como o Estado, a sociedade, o soberano, os súditos existe? 
Como resultado, desponta a defesa de um nominalismo (FOUCAULT, 2008c), segundo o qual o passado que se nos afigura hoje ajusta-se às regras veridictivas definidas pela experiência do próprio presente. Fazer genealogia, assim, seria empreender uma história crítica do presente, em oposição aos universais que esse mesmo presente acredita haver em relação ao que lhe é pregresso.

Desse modo, lograr-se-ia apartar a história da própria discursividade historiográfica, não por tomar esta como imprópria, mas por entender que as categorias de que amiúde ela se vale, mesmo aquelas tratadas como operacionais (a cultura e a economia, por exemplo), seriam concernentes a apenas um entre vários modos de remissão às experiências passadas. Pleiteiase, com isso, a possibilidade de um uso desimpedido do objeto historial - designação quiçá mais precisa para distingui-lo do sentido usual operado pela historiografia - , tal como o que Foucault levou a cabo em suas investigações.

A titubeante aceitação das ideias presentes em História da Loucura [1958] e As palavras e as coisas [1966] entre os historiadores das décadas de 1960 e 1970 acabaria por frustrar as expectativas de Foucault, ainda que alguns adeptos da Nova História - Fernand Braudel e Robert Mandrou, por exemplo - as tenham reputado como correlatas ao que era produzido no âmbito da História das Mentalidades (VEYNE, 2009).

Para outros de seus contemporâneos, principalmente aqueles tributários do marxismo como Jean Paul Sartre -, as formulações de Foucault figuravam descabidas, dada a presumida ausência de esquemas explicativos mais gerais. Pesava para tal objeção, sobretudo, a crença de residir na genealogia foucaultiana uma "[...] limitação objetiva do campo dos instrumentos" de análise (SARTRE, 1978, p. 172), redundando em uma indisposição com a própria historiografia. Em outros casos, como o de Jacques Leonard, a rejeição a Foucault sustentava-se em um argumento quase oposto: o de que ele teria buscado implantar uma filosofia generalizante à história, já que era tão somente um filósofo - pecha que, aliás, foi uma das mais evocadas para desmerecer suas contribuições ao campo historiográfico (O’BRIEN, 1995). Muitos daqueles que subscreveram a crítica de Leonard o fizeram fundados na certeza de que o pensador, estrangeiro ao campo historiográfico, filiava-se à corrente estruturalista ou ao linguistic turn, pondo a perder o diacronismo dos eventos históricos ou mesmo a preponderância destes sobre a linguagem. Entendiam eles que "[...] Foucault reifica uma instância que escapa à ação humana e à explicação histórica, que privilegia os recortes e as estruturas sobre as continuidades ou evoluções, que não se interessa pelo social... Além disso, um termo, o de 'discurso', criou muitas confusões" (VEYNE, 1982, p. 151).

Para Veyne (1982), decorre também dessa associação, ao menos em parte, a suposição de que Foucault seria um relativista, capaz de questionar a realidade de fenômenos concretos como a loucura. Segundo Carlo Ginzburg (1987), outro historiador refratário às proposições de Foucault, este teria se equivocado ao se recusar a interpretar os documentos judiciários e psiquiátricos que abordava, assumindo, em contraste com a Micro-História, uma preocupação maior com os processos de exclusão do que com os excluídos. Concordando com Edward P. Thompson, para quem haveria "[...] muito de charlatão em Foucault" (GINZBURG apud PALLARES-BURKE, 2000, p. 305), o italiano descarta a originalidade da obra de Foucault, reputando-a tão somente como um apêndice de Nietzsche: uma nota de rodapé, em seus termos.

Entre outros historiadores de sua época, todavia, Foucault encontrou apoiadores como Philippe Ariès, Michelle Perrot, Georges Duby e Jacques Le Goff (VEYNE, 2009). Para este último, Foucault havia sim contribuído para a crise da disciplina histórica; contribuição que não seria necessariamente negativa, já que teria possibilitado certa inquietação mediante as verdades triunfantes do campo (LE GOFF, 2003). Daí a defesa de que as críticas de Foucault não configurariam um projeto de degradação da historiografia profissional, mas um esforço de fortalecê-la, pondo em questão algumas de suas premissas irrefletidas. 
A aceitação da obra de Foucault entre os historiadores aumentou significativamente com a publicação na França de Foucault revoluciona a História, em 1978, em que ele é tratado por Veyne (1982, p. 151) como “[...] o historiador acabado, o remate da História". Também colaborou para isso a leitura de Michel de Certeau (1994, p. 131), em 1980: um elogio à abordagem foucaultiana quanto ao caráter prático dos discursos, destacando-se o fato de que, com ele, "[...] a operação teorizante se encontra aí nos limites do terreno onde funciona normalmente, como um carro à beira de uma falésia".

Ainda na década de 1980, outro tipo de ajuizamento do pensamento de Foucault adviria da chamada Nova História Cultural a cargo de Robert Darnton, Roger Chartier e outros, a qual buscava atribuir centralidade às práticas culturais frente às transformações econômicas e sociais, sem com isso tomá-las como totalmente desvinculadas umas das outras. Abrir-se-ia, assim, espaço para uma história da cultura que não passasse diretamente pela história social, e que ainda assim pudesse contemplar os elos entre as práticas culturais e as relações políticas. Para além dos entusiastas ou dos detratores da obra foucaultiana, Roger Chartier (2002, p. 126) é categórico ao indagar:

Deve-se opor Foucault a Foucault e inscrever seu trabalho nas próprias categorias que ele considerava impotentes para dar conta adequadamente dos discursos? Ou se deve submeter sua obra aos procedimentos de análise crítica e genealógica que ela propôs e, consequentemente, anular o que permite delimitar sua unicidade e singularidade? Foucault, sem nenhuma dúvida, estava feliz por ter assim fabricado esta "pequena (e talvez odiosa) maquinaria" que semeia a inquietude no próprio seio do comentário que pretende dizer o sentido da obra.

É fato, pois, que o efeito principal do legado de Foucault parece ser o desencadeamento de, ao menos, uma pronunciada inquietação quanto aos compromissos tácitos dos modos de pesquisar em diferentes campos do saber. Resguardados os devidos limites, é isso também que está em questão, aqui, com relação à História da Educação brasileira. Teria havido impacto do pensamento foucaultiano sobre os pesquisadores da área? Se sim, de quais natureza e monta?

\section{Foucault e a pesquisa brasileira}

A presença das ideias de Foucault nos debates acadêmicos brasileiros confunde-se, em seus primórdios, com a relativa assiduidade de suas visitas ao Brasil entre 1965 e 1976 (RODRIGUES, 2011). Além de suas obras, até então pouco traduzidas para o português, também colaboraram, para os debates filosóficos, médicos e psiquiátricos da época, os registros audiográficos dos seminários e das mesas redondas de que participou em solo brasileiro. Destaque para as conferências ocorridas na PUC-RJ, intituladas A verdade e as formas jurídicas (FOUCAULT, 2001).

Foi nesse contexto que surgiram os primeiros estudos brasileiros de declarada inspiração foucaultiana, tais como Danação da norma (MACHADO et al., 1977) e Ordem médica e norma familiar (COSTA, 1979). Na mesma década, viram-se publicadas as primeiras traduções para o português de estudos de Foucault: Vigiar e punir em 1977 e Microfísica do poder em 1979.

Tais publicações, por sua vez, contribuíram para o posterior espraiamento das teorizações foucaultianas em distintos campos do saber. Entre os historiadores, conforme explicita Margareth Rago (1993, p. 125), tal incidência se deu no cenário de redemocratização do país, em "[...] um momento de intensa contestação social e do deslumbrar de novos possíveis, na virada da década de 70 para os anos 80 ". Tal fato, para a historiadora, ajuda a explicar a razão de os primeiros estudos de história baseados em Foucault terem sido "[...] 
fortemente marcados pelas noções de disciplina, micropolítica, normatização dos gestos, mostrando, cada um a seu modo, a produção do indivíduo pelas malhas do poder" (RAGO, 1993, p. 130). O enfoque nas teorizações acerca das relações poder-saber e seus efeitos subjetivadores seria responsável, ademais, pela associação operada pelos historiadores brasileiros entre as ideias de Foucault e o marxismo heterodoxo de Edward P. Thompson; associação que estaria, para Rago, inscrita na lista de casamentos impossíveis protagonizados por Foucault no pensamento historiográfico do período.

Já no campo educacional, a difusão do pensamento de Foucault remete, segundo Julio G. Aquino (2013), inicialmente à publicação de duas coletâneas de estudos organizadas respectivamente por Tomaz Tadeu da Silva (1994) e Alfredo Veiga-Neto (1995). Tais empreitadas tiveram como marca a crítica às noções de sujeito autônomo e dos efeitos de verdade/poder correlatos às modalidades de conhecimento imperantes no campo pedagógico até então (PARAÍSO, 2004).

Se, nos anos 1990, a corrente de estudos foucaultianos já se mostrava bastante mais vigorosa do que em meados dos anos 1970, outro estudo de Aquino (2018) revela que sua importância nos debates acadêmicos brasileiros não parou de crescer nas duas últimas décadas. Contudo, a constatação de uma espécie de apropriação inercial do pensador, porque da ordem de um catecismo na visão de Silva (2002), parece ser igualmente recorrente, redundando na própria captura de Foucault no expediente do comentário reiterativo.

No que se refere à História da Educação, para Inés Dussel (2004, p. 63), pesquisadora argentina difundida entre os historiadores da educação brasileiros, uma das explicações do prestígio das ideias foucaultianas residiria no potencial renovador de seus escritos, já que por meio deles seria possível refletir "[...] sobre a contingência de nossas formas escolares, de nossas maneiras de pensar o conhecimento, de nossas formas de transmissão e das próprias injustiças que povoam, até mesmo, nossos melhores sonhos pedagógicos". Já Gondra (2005), com vistas a avaliar as apropriações do autor no campo histórico-educacional, entende-as a partir de uma alegada busca da História da Educação por se autonomizar com relação ao campo historiográfico, com vistas à constituição de seus próprios objetos e procedimentos. Nesse sentido, o procedimento historial de Foucault, ao se distinguir das investidas historiográficas clássicas, apresentar-se-ia como lente alternativa a estudos interessados por uma nova identidade epistemológica.

Em direção distinta da conclusão de Gondra, a análise empreendida por Luciano Faria Filho e Diana G. Vidal (2003, p. 60) aponta um uso de Foucault e de outros nomes estrangeiros pelos historiadores da educação impulsionado não pela demanda de se afastarem da História, mas antes para "[...] marcar o seu pertencimento à comunidade dos historiadores, e [...] reafirmar a identificação de suas pesquisas com procedimentos próprios ao fazer historiográfico". O clamor por um maior embasamento teórico das pesquisas históricoeducacionais faria do tipo de aporte conceitual de Foucault, na visão de Faria Filho e Vidal, um aspecto importante a ser observado. Para os referidos autores, tal movimento adviria do incômodo com a presumida subserviência dos estudos histórico-educacionais aos imperativos pedagógicos, bem como às abordagens filosóficas, as quais teriam predominado, segundo os autores, nas pesquisas em educação empreendidas até os anos 1980.

Referidas conclusões pautaram-se na análise de Miriam J. Warde (1984) que, concomitantemente a Jorge Nagle (1984), havia destacado a fragilidade teórica da maior parte das pesquisas de História da Educação até então realizadas, reclamando uma maior interação com as ciências sociais, em especial com a História, como meio para o fortalecimento do campo. Com isso, Warde (1984) esperava que fosse possível superar o presentismo e pragmatismo característicos de tais investigações, bem como o caráter propositivo dos estudos a eles associados, favorecendo pesquisas de cunho mais analítico. 
Nas décadas seguintes, o ponto de vista de Warde e de Nagle quanto à incipiência dos debates teóricos no campo histórico-educacional viu-se endossado por outros pesquisadores, reforçando também a defesa de um maior diálogo envolvendo historiadores da educação e seus pares de outras áreas (BONTEMPI JR.; TOLEDO, 1993; SAVIANI, 1998). Nesse cenário, uma série de pensadores estrangeiros aos domínios histórico-educacionais, historiadores ou não, teria sido incorporada ao campo, estando Foucault, à época, entre os cinco mais citados nos estudos da área (FARIA FILHO; VIDAL, 2003).

Entretanto, para outros pesquisadores da História da Educação que herdaram a visão negativa de parte da historiografia acerca do "paradigma pós-moderno" (CARDOSO, 1994), do qual Foucault supostamente seria tributário, a presença do pensador francês nos estudos históricoeducacionais apresentar-se-ia mais como um perigo do que uma alternativa às inflexões do campo. Foi o caso de Dermeval Saviani (1998, p. 16), para quem Foucault fazia parte de uma tendência cujo alastramento no campo histórico-educacional precisaria ser contido, em favor "[...] da preocupação de investigar a História da Educação pela mediação da Sociedade, o que indica a busca de uma compreensão global da educação em seu desenvolvimento".

A visão do pensamento de Foucault como pária dos debates historiográficos não cessaria nos anos posteriores, como atesta Durval Albuquerque Júnior (2004, p. 97):

Todo o seu trabalho no campo historiográfico é desqualificado com meia dúzia de opiniões e palpites, sendo quase sempre atingida sua pessoa e não seu pensamento. [...] Foucault é sempre tratado como um invasor do campo, como alguém que, inclusive, quis acabar com a história, mesmo que tenha dedicado toda a sua vida a fazê-la e tenha se mostrado um praticante criativo de nosso métier, estimulando uma ampla produção na área.

Tais reverberações de Foucault, passadas quatro décadas do posicionamento de Veyne quanto ao caráter revolucionário dos estudos do francês, indicam que os embates teóricos concernentes ao encontro entre Foucault e a História não cessaram. Transpostas para o campo da História da Educação, tais dissonâncias demonstram, a nosso ver, a necessidade de se ter em conta as implicações do emprego do referencial foucaultiano nos estudos conduzidos nessa seara e, em particular, os elementos teórico-metodológicos que aí se viram desestabilizados ou, de modo oposto, reforçados.

\section{Foucault e a pesquisa brasileira em História da Educação}

Interessados pela concretude das pesquisas histórico-educacionais brasileiras que se valeram do diálogo com as ideias foucaultianas, enveredamos pela produção veiculada pelos três principais periódicos brasileiros devotados à História da Educação. Trata-se, cremos, de uma mostra suficientemente abrangente daquilo que se configurou na área, em que pese o fato de que tal seleção não recobre o espectro integral das pesquisas, uma vez que a produção textual se distribui igualmente por vários outros periódicos não específicos do campo educacional.

Assim, foram selecionados, ao todo, 111 artigos em que constou alguma obra foucaultiana nas referências ali mobilizadas. A saber: História da Educação: 36 artigos; Revista Brasileira de História da Educação: 36; e Cadernos de História da Educação: 39. Em tempo, foram excluídos os artigos de autores estrangeiros nos três periódicos, uma vez que o escopo deste trabalho voltou-se apenas à produção dos pesquisadores brasileiros.

Em seguida, foram discriminados aqueles textos em que se constatou um uso efetivo das ideias de Foucault na argumentação; de maneira distinta, portanto, de um uso contingente delas. O uso efetivo descreve uma apropriação mais sistemática e articulada do autor à argumentação 
propriamente, podendo dar-se em diferentes níveis ou patamares (o que será discutido adiante), ao passo que o uso contingente é definido como uma apropriação não substantiva - e muitas vezes apenas incidental e/ou cirúrgica - das ideias do autor citado, sem relação aparente com o enquadre teórico predominante empregado no texto.

Assim, foram selecionados 42 textos cujo teor apontava para uma relação mais estrita ou focal em relação ao pensamento foucaultiano: 15 em História da Educação; 09 em Revista Brasileira de História da Educação; 18 em Cadernos de História da Educação. Note-se que, apesar de contar com um número menor de fascículos publicados, ${ }^{1}$ o último periódico apresentou o dobro de textos de Revista Brasileira de História da Educação.

Os textos que apresentaram um uso efetivo das ideias foucaultianas são:

\section{Em História da Educação:}

- POSSAMAI, Zita Rosane. A grafia dos corpos no espaço urbano: os escolares no álbum Biografia duma cidade, Porto Alegre, 1940. 2015.

- WITCHS, Pedro Henrique; LOPES, Maura Corcini. Educação de surdos e governamentalidade linguística no Estado Novo (Brasil, 1934-1948). 2015.

- ALMEIDA, Cíntia Borges de; NEVES, Dimas Santana Souza; GONDRA, José Gonçalves. Ensino obrigatório: "Prudente é esperar-se do tempo o preciso remédio". 2012.

- BORGES, Angélica. Por uma disciplina rigorosa e ilustrada: a Inspeção na Capital do Império. 2012.

- SOUZA, Maria Zélia Maia de. Governo de crianças: o Instituto Profissional João Alfredo (1910-1933). 2012.

- FISCHER, Beatriz T. Daudt. Revista do Ensino/RS e Maria de Lourdes Gastal: duas histórias em conexão. 2010.

- TEIVE, Gladys Mary Ghizoni. Grupo escolar e produção do sujeito moderno: um estudo sobre o currículo e a cultura escolar dos primeiros grupos escolares catarinenses (19111935). 2009.

- GONDRA, José Gonçalves. Entre o cura e o médico: higiene, docência e escolarização no Brasil Imperial. 2007.

- SILVA, Nilce da. Da "Revolução Francesa" ao "Século XXI": algumas notas acerca do sistema educacional francês. 2007.

- CARVALHO, Rodrigo Saballa de. A emergência das instituições de Educação Infantil. 2006.

- FISCHER, Beatriz T. Daudt. As caixas de papéis de Nilce Lea: memórias e escritas de uma simples professora? 2005.

- ROCHA, Cristianne Maria Famer. Espaços escolares: modernizações produtivas. 2000

- GAMA, Zacarias Jaegger; GONDRA, José Gonçalves. Uma estratégia de unificação curricular: "Os Estatutos das Escolas Públicas de Instrução Primária" (Rio de Janeiro 1865). 1999.

- FISCHER, Beatriz Daudt. Foucault e histórias de vida: aproximações e quetais. 1997.

- STEPHANOU, Maria. Práticas educativas da medicina social: os médicos se fazem educadores. 1997.

\footnotetext{
${ }^{1}$ Desde sua fundação, os três periódicos publicaram, respectivamente: História da Educação: 56 fascículos; Revista Brasileira de História da Educação: 47; e Cadernos de História da Educação: 31.
} 


\section{Em Revista Brasileira de História da Educação:}

- SANTOS, Flavio Tito Cundari da Rocha; AQUINO, Julio Groppa. As 'Cartas de Formação' de Mário de Andrade (1924-1945) e sua potência educativa. 2017.

- MENEZES, Antônio Basílio Novaes Thomaz de; SILVA, Juliana da Rocha e. O ensino escolar que disciplina e normaliza: Luiz Antonio dos Santos Lima e as medidas de correção contidas em Hygiene Mental e Educação (1927). 2016.

- CARVALHO, Eliane Vianey de; ABREU JUNIOR, Laerthe de Moraes. O combate à "degeneração da raça": discurso educativo para a população na legislação da saúde pública de Minas Gerais em 1927. 2015.

- CONCEIÇÃO, Joaquim Tavares da. 'Vícios execráveis' campanha médica de combate à masturbação e à homossexualidade entre os pensionistas de colégios-internatos (18451927). 2015.

- VIVIANI, Luciana Maria. A Biologia Educacional: exercitação e propostas inovadoras em um periódico educacional paulista (1938-1941). 2015.

- GUIMARÃES, Paula Cristina David. "Tudo presta a quem tudo precisa": os discursos sobre a escolarização da infância pobre, presentes na Revista do Ensino, de Minas Gerais (1925-1930). 2013.

- RITO, Marcelo; AQUINO, Julio Groppa. Natureza, infância e ciência no Brasil dos anos 1920/30: a pedagogia moderna e a Bibliotheca de educação. 2012.

- NEVES, Dimas Santana Souza. Poder e cultura escolar na Primeira República em Mato Grosso. 2007.

- PAULILO, André. O avesso das normas: indolentes, vadios, imprudentes e outros tipos escolares. 2007.

\section{Em Cadernos de História da Educação:}

- RIPE, Fernando. "Se hum instante vos descuidais, se hum instante desamparais vosso filho, talvez que para sempre fique perdido": vigilância e punição em um manual de Comportamento Social português do século XVIII. 2017.

- CASTRO, Cesar Augusto; CASTEllanOS, Samuel Luis Velazquez. As doenças e o controle dos desejos corporais dos meninos recolhidos em instituições educativas maranhenses no oitocentos. 2016.

- GUIDO, Humberto. A história social da criança: subsídios para a pesquisa historiográfica da infância (1530-1599). 2015.

- ELIAS, Aluizio Ferreira; RESENDE, Haroldo de. A criança ajustada: aspectos do pensamento de Dante Moreira Leite sobre a infância urbana brasileira. 2014.

- GONÇALVES NETO, Wenceslau. "Educação christã da mocidade": regulamentação da vida escolar em colégios católicos de Minas Gerais (1863-1911). 2014.

- HICKMANN, Roseli Inês. Dos direitos declarados: uma história (re)contada sobre a infância de direitos. 2014.

- CALDEIRA-MACHADO, Sandra Maria; BICCAS, Maurilane de Souza; FARIA FILHO, Luciano Mendes de. Estatísticas educacionais e processo de escolarização no Brasil: implicações. 2013.

- CARDOSO, Maurício Estevam. Por uma história cultural da educação: possibilidades de abordagens. 2011.

- GUIMARÃES, Paula Cristina David. O discurso médico sobre a educação da infância pobre veiculado pela Revista do Ensino de Minas Gerais (1925-1930). 2011.

- LIMA, Solyane Silveira; BERGER, Miguel André. A Casa Maternal Amélia Leite (19471970): uma instituição educativa de proteção à maternidade e a infância. 2011.

- RESENDE, Haroldo de. Vigiar, punir e educar: o "sistema educacional" da prisão. 2010. 
- ABREU JUNIOR, Laerthe de Moraes; FERNANDES, Michele Longatti; NEVES, Ellen Pereira. Na periferia da cidade, à margem dos processos educativos: memórias de experiências escolares de moradores do bairro de São Geraldo em São João Del-Rei. 2008.

- DURÃES, Sara Jane Alves; AGUIAR, Fátima Rita Santana. Os grupos escolares mineiros como lugar de disciplina e higienização dos corpos. 2008.

- MANKE, Lisiane Sias; PERES, Eliane. Os cadernos comprovantes como dispositivos de controle do trabalho docente: uma contribuição à história da profissão docente. 2008.

- ALVES FILHO, Eloy; SALCIDES, Arlete Maria Feijó. Vantagens da alfabetização na perspectiva de adultos residentes em áreas rurais do Brasil e de Portugal. 2007.

- ALMEIDA, Maria de Fátima Ramos de. Política educacional brasileira na década de 1990: um desserviço à cidadania. 2005.

- BERGER, Miguel André. Igreja X educação: o papel do colégio Nossa Senhora de Lourdes na formação da elite feminina. 2004.

- TOFOLI, Therezinha Elizabeth. Educação feminina no Colégio Madre Clélia de Adamantina-SP. 2004.

Trata-se, ao todo, de 50 diferentes autores vinculados aos textos selecionados, sendo que 42 deles figuraram apenas uma vez. Entre os restantes, dois autores figuraram três vezes: Beatriz T. Daudt Fischer e José Gonçalves Gondra. Outros seis, duas vezes: Dimas Santana Souza Neves; Haroldo de Resende; Julio Groppa Aquino; Laerthe de Moraes Abreu Junior; Miguel André Berger; e Paula Cristina David Guimarães. As 19 instituições às quais os/as 50 autores/as declararam sua filiação são as seguintes:

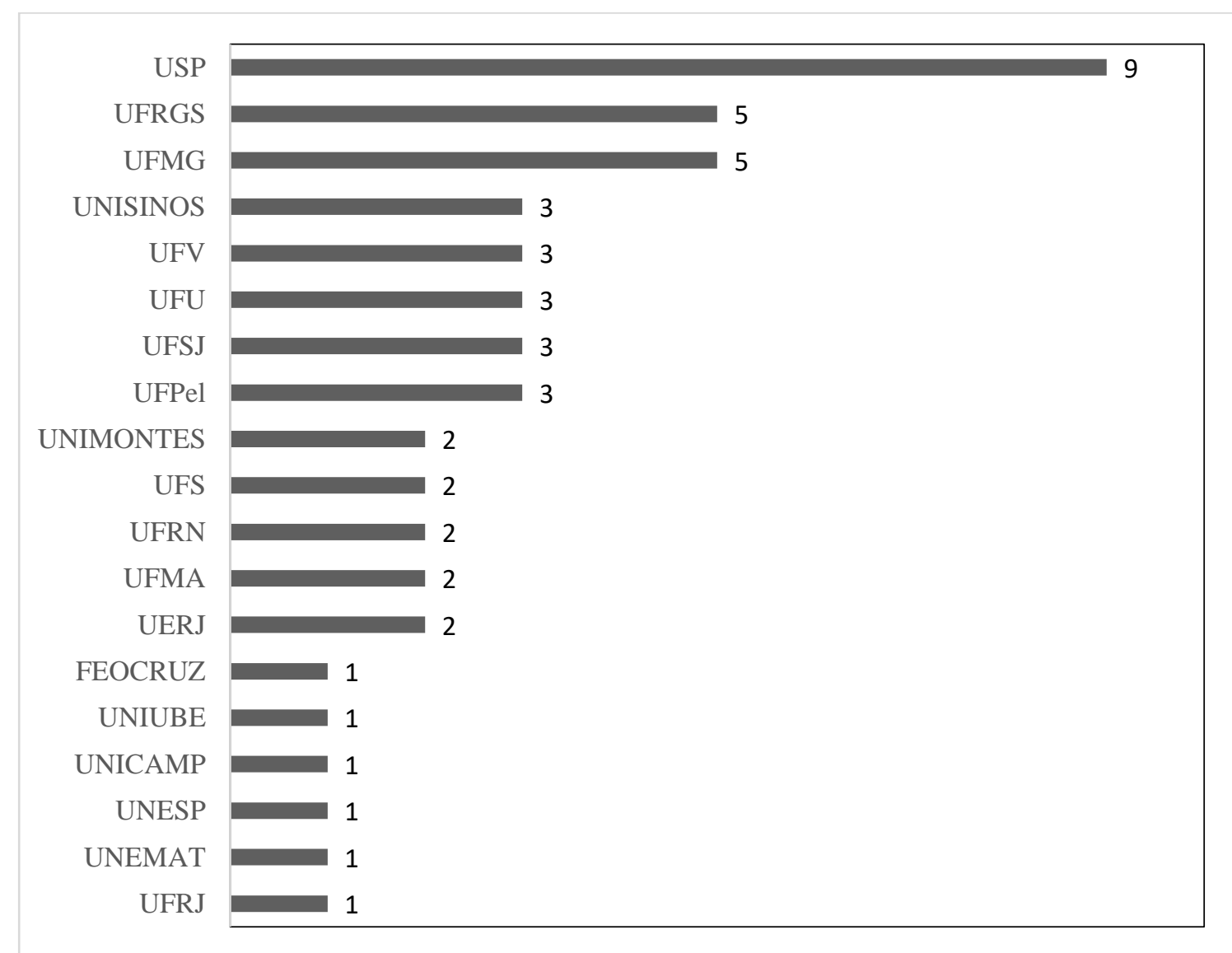


Quanto ao escopo temporal da produção, os 21 anos entre 1997 e 2017 foram subdivididos em três faixas: o período 1997-2003 contou com apenas quatro textos publicados (10\%); já entre 2004 e 2010, foram 16 textos (38\%), ao passo que $22(52 \%)$ vieram a público nos anos posteriores (2011-2017). Mostra de um crescimento do interesse pelo legado foucaultiano? Não se poderia afirmá-lo categoricamente, conforme se verá a seguir.

No que diz respeito ao teor do emprego das ideias foucaultianas, um primeiro elemento considerado foram as remissões efetivas à obra do pensador, as quais se dividiram entre os livros, os cursos e os textos esparsos do francês. Nessa direção, os livros consistem no suporte textual mais visitado pelos pesquisadores. E apenas cinco das obras de Foucault, ao todo, foram citadas. Vigiar e punir (em 19 dos 42 textos); A arqueologia do saber (em 11); A ordem do discurso (em seis); História da sexualidade I (em seis); História da sexualidade II (em dois); e História da sexualidade III (em apenas um texto).

Em segundo lugar, destacam-se os textos esparsos e afins. Trata-se de Microfísica do poder (19 vezes); Ditos e Escritos (cinco); O que é um autor? (quatro); os textos inseridos em Michel Foucault, uma trajetória filosófica (três); A verdade e as formas jurídicas (três), os textos constantes das edições em espanhol: Las redes del poder (uma) e Tecnologías del yo (uma).

Os cursos, por sua vez, constituem o suporte textual menos visitado pelos pesquisadores. Foram referidos: Em defesa da sociedade (em seis textos); Segurança, território, população (em quatro), O governo de si e dos outros (em dois); Nascimento da biopolítica (em dois); O poder psiquiátrico (em um); Os anormais (em um); A hermenêutica do sujeito (em um); A coragem da verdade (em um). O Resumo dos cursos no Collège de France foi citado duas vezes.

Adentrando o âmbito argumentativo de cada um dos 42 artigos selecionados, temos que os materiais analisados subdividem-se entre: documentos oficiais (em 11 estudos); periódicos e livros (em nove); depoimentos (em sete); documentos de instituições específicas (em cinco); escritos de médicos (em cinco); correspondências e arquivos pessoais (em três); material iconográfico (em três); material escolar (em um). No caso dos ensaios teóricos (cinco deles), foram mobilizadas obras de teóricos da educação e de outros campos.

As noções teóricas foucaultianas preponderantes nos textos são as seguintes: disciplina (19 vezes); discurso (nove); governamentalidade (nove); biopolítica (cinco) arqueologia/arqueogenealogia (três); genealogia (três); poder (duas); subjetivação (duas); verdade (duas); arquivo (uma); foco de experiência (uma); função-autor (uma).

Há, por fim, duas distinções operacionais que merecem menção:

1) Os textos em que a noção de genealogia é genericamente evocada nos fundamentos teórico-metodológicos da empreitada. Trata-se de quatro ocorrências:

- CARDOSO, Maurício Estevam. Por uma história cultural da educação: possibilidades de abordagens. Cadernos de História da Educação, 2011;

- CARVALHO, Rodrigo Saballa de. A emergência das instituições de Educação Infantil. História da educação, 2006.

- FISCHER, Beatriz T. Daudt. Revista do Ensino/RS e Maria de Lourdes Gastal: duas histórias em conexão. História da Educação, 2010;

- FISCHER, Beatriz Daudt. Foucault e histórias de vida: aproximações e quetais. História da Educação, 1997.

2) Os textos em que Foucault aparece de modo longitudinal na argumentação, recobrindo desde a circunscrição temática do problema eleito, passando pelo aporte metodológico, até a discussão dos resultados propriamente. Nesse caso, apenas três dos 42 textos registraram tal constância: 
- CARVALHO, Rodrigo Saballa de. A emergência das instituições de Educação Infantil. História da educação, 2006.

- FISCHER, Beatriz Daudt. Foucault e histórias de vida: aproximações e quetais. História da Educação, 1997; e

- RESENDE, Haroldo de. Vigiar, punir e educar: o "sistema educacional" da prisão. Cadernos de História da Educação, 2010.

\section{À guisa de conclusão}

Atenta tanto aos artigos em seu conjunto quanto às especificidades de cada um deles de modo a dar a ver movimentos simultâneos, não obstante descentrados -, a dissecação do corpus analítico eleito não pretendeu empreender nenhum tipo de comparação entre aquilo que foi praticado por Foucault e os intentos investigativos dos historiadores da educação brasileiros. Tal expediente ajuizador, decerto, poderia incorrer na constatação de textos supostamente menores quando comparados com a obra do pensador ou, mais radicalmente, na arriscada apuração de peças satisfeitas em replicar - de maneira mal ou bem-sucedida, tanto faz - os parâmetros analíticos de Foucault sobre algum objeto investigativo distinto daqueles sobre os quais ele próprio se deteve.

Em vez disso, admitimos a potência da circulação recriadora dos discursos, na esteira da qual os usos de determinado autor e seus respectivos desdobramentos são reinventados a cada vez, comportando, assim, uma gama de efeitos indeterminados, posto que não necessariamente coincidentes nem entre si, nem com uma suposta unidade autoral de base. Em suma, instamo-nos, ao gosto do próprio Foucault, a recusar a instância autoral como marco fundador.

Mesmo refratando qualquer esforço de mimese autoral, salta-nos aos olhos, entretanto, um detalhe digno de menção: nenhum dos artigos mobilizados contou com Nietzsche, $a$ genealogia, a história entre suas referências. A presumível discrição ou, no limite, a abstenção dos pesquisadores em relação ao Foucault genealogista finda por desaguar, parece-nos, em um dos dois contextos seguintes: ou a operação genealógica teria se entranhado nos estudos ao ponto de não deixar rastros autorais, ou as análises efetuadas, ainda calcadas em procedimentos historiográficos sedimentados, se valeram de elementos esparsos do pensamento foucaultiano, sem compartilhar do arcabouço genealógico a ele conexo. E, tudo leva crer, a segunda alternativa parece ser a mais provável.

A despeito de uma patente rarefação do leitmotiv genealógico nos estudos brasileiros em História da Educação apoiados em Foucault, é possível concluir que há vários Foucaults em jogo nesse quadrante, tratando-se, a rigor, de um gradiente volátil quanto à incorporação de suas ideias nos modos de pesquisar aí em curso. E, se correto for tal ponto de vista, restar-nos-ia uma questão de fundo: em quais circunstâncias e sob quais condições seria possível designar foucaultiano certo tipo de exercício investigativo de matriz historial independentemente, aliás, da afiliação disciplinar de quem o opera? Às lentes de Artières (2016, p. 386):

Fazer a análise do microdispositivo de poder, compreender como no momento de determinado acontecimento, por menor que seja - um motim numa prisão ou então a redação de uma memória autobiográfica -, algo de inédito emerge: surge uma força que subitamente vem modificar o estado das coisas. Tentar fazer a crônica dessas sublevações, desses instantes de subjetivação é talvez verdadeiramente tentar inscrever seu trabalho nos passos de Foucault. 
O registro analítico a que Artières se refere recobre novamente o gesto genealógico e suas exigências teóricas (o acontecimento sub-reptício produtor de diferença) e metodológicas (a crônica historial dos pontos de virada e seu condão subjetivador). Daí que, antes da adesão mais, ou menos, explícita a determinadas formulações consensuais entre os seguidores/comentadores de Foucault, mais conta a fibra procedimental da investida analítica que se queira afinada ao pensador; isto é, suas pegadas, jamais seu compasso.

Tratar-se-ia, em suma, de honrar Foucault pelo gesto não de esquecê-lo, mas de subsumi-lo ao próprio agir. Canibalizá-lo, quiçá.

\section{Referências}

ALBUQUERQUE JÚNIOR, Durval M. História em jogo: a atuação de Michel Foucault no campo da historiografia. Anos 90, Porto Alegre, v. 11, n. 19/20, p. 79-100, jan./dez. 2004. https://doi.org/10.22456/1983-201X.6352

AQUINO, Julio G. A difusão do pensamento de Michel Foucault na Educação brasileira: um itinerário bibliográfico. Revista Brasileira de Educação, Rio de Janeiro, v. 18, n. 53, p. 301324, abr./jun. 2013. https://doi.org/10.1590/S1413-24782013000200004

AQUINO, Julio G. Foucault e a pesquisa educacional brasileira, depois de duas décadas e meia. Educação \& Realidade, Porto Alegre, v. 43, n. 1, p. 45-71, jan./mar. 2018. https://doi.org/10.1590/2175-623661605

ARTIÈRES, Philippe. Foucaultiano, adjetivo masculino? In: RODRIGUES, Heliana B. C.; PORTOCARRERO, Vera; VEIGA-NETO, Alfredo. (Orgs.). Michel Foucault e os saberes do homem: como, na orla do mar, um rosto de areia. Curitiba: Prismas, 2016. p. 382-389.

AZEREDO, Vânia Dutra de. A metodologia de Foucault no trato dos textos nietzschianos. Cadernos Nietzsche, São Paulo, v. 1, n. 35, p. 57-85, 2014. https://doi.org/10.1590/S2316$\underline{82422014000200004}$

BONTEMPI JR., Bruno; TOLEDO, Maria Rita. Historiografia da educação brasileira: no rastro das fontes secundárias. Perspectiva, Florianópolis, n. 20, p. 9-30, 1993.

CARDOSO, Ciro F. Paradigmas rivais na historiografia atual. Educação \& Sociedade, Campinas, n. 47, p. 61-72, abr. 1994.

CARVALHO, Alexandre Filordi de. Foucault: atualizador da genealogia nietzschiana. Cadernos Nietzsche, São Paulo, n.30, p.221-249, 2012.

CERTEAU, Michel de. A invenção do cotidiano. Rio de Janeiro: Vozes, 1994.

CHARTIER, Roger. À beira da falésia: a história entre certezas e inquietude. Porto Alegre: UFRGS, 2002.

COSTA, Jurandir F. Ordem médica e norma familiar. Rio de Janeiro: Edições Graal, 1979.

DEFERT, Daniel. Cronologia. In: FOUCAULT, Michel. Problematização do sujeito: psicologia, psiquiatria e psicanálise. Rio de Janeiro: Forense Universitária, 2014. p. 1-70. 
DUSSEL, Inés. Foucault e a escrita da história: reflexões sobre os usos da genealogia. Educação \& Realidade, Porto Alegre, v. 29, n.1, p. 45-68, jan./jun. 2004.

FARIA FILHO, Luciano; VIDAL, Diana. História da Educação no Brasil: a constituição histórica do campo (1880-1970). Revista Brasileira de História, São Paulo, v. 23, n. 45, p. 37-70, 2003. https://doi.org/10.1590/S0102-01882003000100003

FOUCAULT, Michel. Aulas sobre a vontade de saber. São Paulo: WMF Martins Fontes, 2018.

FOUCAULT, Michel. Do governo dos vivos: curso do Collège de France (1979-1980). São Paulo: WMF Martins Fontes, 2014a.

FOUCAULT, Michel. Loucura, literatura, sociedade. In: Problematização do sujeito: psicologia, psiquiatria e psicanálise. Rio de Janeiro: Forense Universitária, 2014b. p. 232-258.

FOUCAULT, Michel. Nietzsche, a genealogia, a história. In: Arqueologia das ciências e história dos sistemas de pensamento. Rio de Janeiro: Forense Universitária, 2008a. p. 260-281.

FOUCAULT, Michel. Estruturalismo e pós-estruturalismo. In: Arqueologia das ciências e história dos sistemas de pensamento. Rio de Janeiro: Forense Universitária, 2008b. p. 307-334.

FOUCAULT, Michel. Nascimento da biopolítica. São Paulo: Martins Fontes, 2008c.

FOUCAULT, Michel. Nietzsche, Freud, Marx. In: Arqueologia das ciências e história dos sistemas de pensamento. Rio de Janeiro: Forense Universitária, 2008d. p. 40-55.

FOUCAULT, Michel. A verdade e as formas jurídicas. Rio de Janeiro: Nau, 2001.

FOUCAULT, Michel. A arqueologia do saber. Rio de Janeiro: Forense Universitária, 1987.

GONDRA, José G. Paul-Michel Foucault - uma caixa de ferramentas para a História da Educação? In: FARIA FILHO, Luciano M. (Org.). Pensadores sociais e História da Educação. Belo Horizonte: Autêntica, 2005. p. 293-311.

GINZBURG, Carlo. O queijo e os vermes: o cotidiano e as idéias de um moleiro perseguido pela Inquisição. São Paulo: Companhia das Letras, 1987.

LE GOFF, Jacques. Foucault e a nova história. Plural, São Paulo, n.10, p.197-209, jul./dez. 2003.

MACHADO, Roberto; LOUREIRO, Ângela; LUZ, Rogério; MURICY, Kátia. Danação da norma: a medicina social e constituição da psiquiatria no Brasil. Rio de Janeiro: Graal, 1977.

MARTON, Scarlett. Foucault leitor de Nietzsche. In: RIBEIRO, Renato Janine. (Org.) Recordar Foucault. São Paulo: Brasiliense, 1985, p. 36-46.

NAGLE, Jorge. História da Educação Brasileira: problemas atuais. Em Aberto, Brasília, v. 3, n. 23, p. 27-29, set./out. 1984. 
O’BRIEN, Patrícia. A história cultural de Michel Foucault. In: HUNT, Lynn. (Org.). A nova história cultural. São Paulo: Martins Fontes, 1995, p. 33-62.

PALLARES-BURKE, Maria Lúcia. Carlo Ginzburg. In: As muitas faces da história (nove entrevistas). São Paulo: Ed. Unesp, 2000. p. 269-306.

PARAÍSO, Marlucy A. Pesquisas pós-críticas em educação no Brasil: esboço de um mapa. Cadernos de pesquisa, São Paulo, v. 34, n. 122, p. 283-303, maio/ago. 2004. https://doi.org/10.1590/S0100-15742004000200002

RAGO, Luzia Margareth. As marcas da pantera: Michel Foucault na historiografia brasileira contemporânea. Anos 90, Porto Alegre, v. 1, n. 1, p.121-143, 1993. https://doi.org/10.22456/1983$\underline{\text { 201X.6120 }}$

RODRIGUES, Heliana B. C. Michel Foucault no Brasil: esboços de história do presente. Verve, São Paulo, n. 19, p. 93-112, 2011.

SARTRE, Jean-Paul. Questão de Método. In: Col. Os Pensadores. São Paulo: Abril Cultural, 1978. p. 115-197.

SAVIANI, Dermeval. O debate teórico e metodológico no campo da história e sua importância para a pesquisa educacional. In: SAVIANI, Dermeval; LOMBARDI, José; SANFELICE, José. (Orgs.) História e História da Educação: o debate teórico-metodológico atual. Campinas: Autores Associados/HISTEDBR, 1998. p. 7-15.

SILVA, Tomaz T. (Org.). O sujeito da educação: estudos foucaultianos. Petrópolis: Vozes, 1994.

SILVA, Tomaz T. (Org.). Mapeando a [complexa] produção teórica educacional. Currículo sem Fronteiras, v. 2, n. 1, p. 5-14, 2002.

VEIGA-NETO, Alfredo (Org.). Crítica pós-estruturalista e educação. Porto Alegre: Sulina, 1995.

VEYNE, Paul. Como se escreve a história. Foucault revoluciona a história. Brasília: UnB, 1982.

VEYNE, Paul. Foucault, o pensamento, a pessoa. Lisboa: Texto e Grafia, 2009.

WARDE, Mirian J. Anotações para uma historiografia da Educação brasileira. Em aberto, Brasília, v. 3, n. 23, p. 3-11, set./out. 1984. 